\title{
The Effect of Wind Turbine Infrasound Emission on Subjectively Rated Activation Level
}

\author{
C. KAsprzaK ${ }^{a, *}$, E. SkrodzKa ${ }^{b}$ AND J. Wiciak ${ }^{a}$ \\ ${ }^{a}$ AGH University of Science and Technology, Faculty of Mechanical Engineering and Robotics, \\ Department of Mechanics and Vibroacoustics, Al. A. Mickiewicza 30, 30-059 Krakow \\ ${ }^{b}$ Institute of Acoustics, A. Mickiewicz University, Umultowska 85, 61-614 Poznań, Poland
}

\begin{abstract}
The problem of low-frequency acoustic waves emitted by wind turbine farms has become a great challenge to acousticians in Europe for more than 20 years. In Poland wind farm industry is growing rapidly and generates questions about the influence of such sounds on human organism. A short survey of previously published reports concerning subjectively perceived influence of wind turbines on people living next to wind farms is given together with the results of the Thayer's test measuring the difference in activation level before and after exposition on infrasound wave generated by a wind turbine. Statistically significant increase of the High Activation Level representing a tension type arousal has been revealed.
\end{abstract}

DOI: 10.12693/APhysPolA.125.A-45

PACS: 87.50.Y-, 43.28.Dm, 87.19.Lr

\section{Introduction}

Energy acquisition from wind turbines grows very dynamically all over the world, including Poland. Development of the wind power industry in Poland is an effect of, among other thing, favorable wind conditions. On the grounds of long-standing research carried out by the Institute of Meteorology and Water Management in Warsaw [1] it was found that conditions favorable for location and development of wind farms prevail on the area encompassing nearly $2 / 3$ of the territory of Poland. In the above-mentioned part of the territory of Poland, the annual average wind speed exceeds $4 \mathrm{~m} / \mathrm{s}$ and is therefore sufficient for cost-effective operation of wind turbines. In fact, most of modern turbine types can be effectively operated at wind speeds in the range $4-25 \mathrm{~m} / \mathrm{s}$.

There is a relatively small number of standards concerning the impact of wind power plants on the environment and assessment reports dealing with this issue. Most of them pertain to hazardous (and not arduous or annoying) noise generated by wind farms.

Despite the undeniable fact that modern wind turbines generate much less noise than their precursors, their impact on human life becomes more and more noticeable. That type of noise, in specific weather conditions, propagates over much larger distances and reaches much higher values (by about 10-15 dB) than those calculated from numerical models [2]. In most cases this is an impact perceived subjectively, i.e. presence of wind turbines induces acoustic and extra-acoustic annoyance (distraction, irritation). These factors, determined mainly on the grounds of modeled sound levels and questionnaire surveys (carried out especially in The Netherlands and in Sweden), are related to the level and spectral content of the sound

*corresponding author; e-mail: cekasp@agh.edu.pl generated by turbines and emitted to the surrounding environment, including regions populated by people, as well as to the time of the day, weather conditions (wind speed and direction), personal attitude to wind power business (enthusiasts - opponents), distance to the nearest wind farm, or age of the respondents [3-11].

Moreover, the noise generated by wind farms is assessed as more annoying then transportation and industrial noise [11]. As the sound emitted by wind farms is a relatively new type of noise to which large communities would be exposed, any "dose-response" curves based on extensive measurements are still hardly available. The curves, well known for transportation and industrial types of noise [12], although extremely important from the point of view of the necessity to determine the maximum allowable exposure to noise with respect to its annoying effect, are currently just in the stage of development [7, 10, 11].

In Poland, currently only about $0.7 \%$ of electric energy is acquired from the power of wind. To date, no comprehensive research was carried out in our country on the impact of sound generated by wind farms on comfort of people living in the vicinity of wind farms, although the problem as such has been already noticed [13]. In view of the observed dynamic growth the of wind power business and plans of its further development, one should expect that problems similar to those arising in the countries where a significant fraction of energy is obtained from wind farms will be soon encountered also in Poland.

\section{Subjective assessment of the impact of sound emitted by wind farms}

Data on subjective assessment of sound emitted by wind farms were acquired by means of questionnaire surveys conducted among people living close to wind farms $[6,7,10]$. The subject of the research were verbal descriptions of the sound generated by wind turbine units and subjective sensation of loudness for different wind conditions, as well as the effect of extra-acoustic 
factors (economic benefits derived from wind farms, possible visibility from inside, dwelling location) on perceptibility and annoyance of these sounds.

Figure 1 shows results of questionnaire surveys carried out in The Netherlands, in which the respondents were asked to point out an expression describing in a best way the sound generated by wind power plants. The respondents lived at a distance of $2,5 \mathrm{~km}$ from the plant. The figure illustrates results of the questionnaire survey with the respondents divided into those who felt annoyance induced by wind turbine sound and those who did not have such sensation [10].

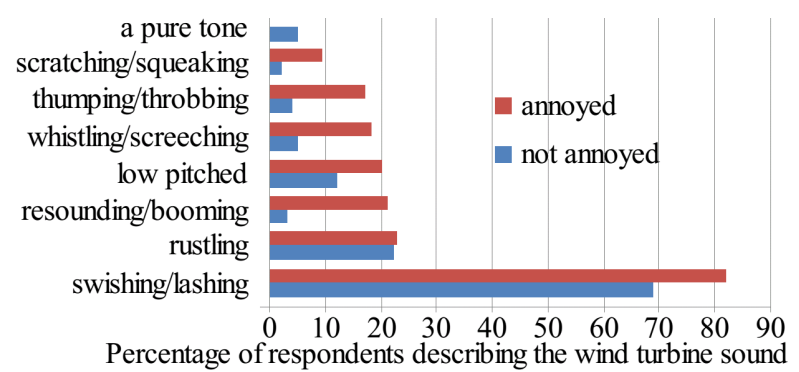

Fig. 1. Results of survey questionnaires carried out in The Netherlands. The respondents were asked to point out a verbal description representing in a best way the sound generated by win power turbines [10].

A description frequently selected in both of the described above groups with different sensitivity to presence of wind farms, was " swishing/lashing" [7, 10, 11]. Statistical correlation of the description "swishing/lashing" with annoyance was significant $(r=0.72)$.

In Fig. 2, results of a questionnaire survey carried out in The Netherlands are presented concerning circumstances in which the audibility of sound generated by wind turbines is increased [11]. As it could be expected, most of respondents assessed these sounds as louder ones at stronger wind blowing towards their houses.

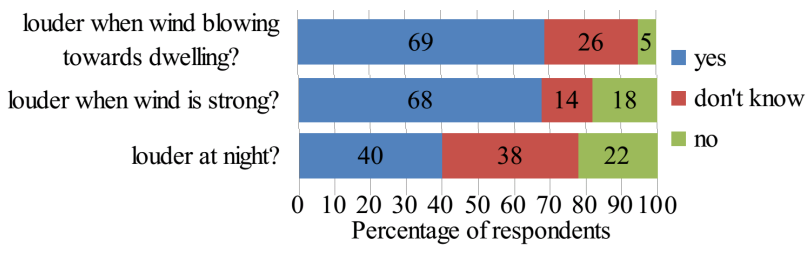

Fig. 2. Results of survey questionnaires carried out in The Netherlands. The respondents were asked to determine the effect of wind direction and strength on subjective perception of sound generated by wind power plants as well as its subjective loudness in the nighttime [10].

Somewhat surprising were answers to the question about loudness in the night: for $22 \%$ of respondents, the sound was quieter in the night than during the daytime, while the fractions of respondents claiming that the sound in the night was louder or comparable were almost equal to each other ( $40 \%$ and $38 \%$, respectively). In earlier papers, noise perceived in the night was described as very annoying [2]. This divergence can be related to the fact that average height of wind turbine towers is increasing by the year, as shown in Fig. 3 .

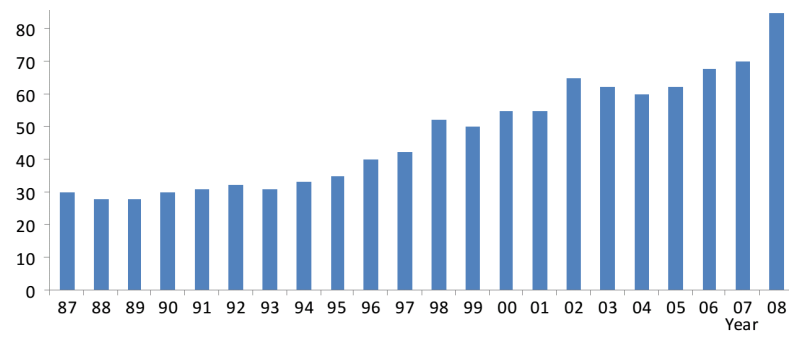

Fig. 3. Average height of wind turbine tower in The Netherlands [9].

Annoyance of sound generated by wind turbines was compared to this caused by transportation and industrial noise $[7,10,11,14]$. Fig. 4 shows the percentage of respondents to survey questionnaires who derived no benefits from wind farms and felt high annoyance of the noise emitted by wind turbines outside their dwellings. The dose-response curves did not differentiate between annoyance outside and inside houses.

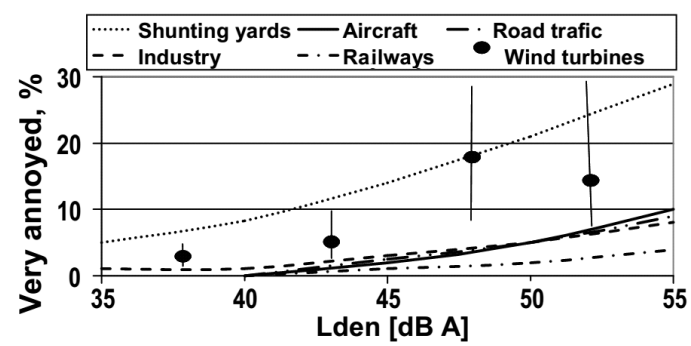

Fig. 4. The percentage of respondents in The Netherlands (not receiving economic benefits from wind farms) sensing high annoyance caused by wind turbines outside their dwellings. For comparison, annoyance levels of transportation, railway, aviation, industrial, and shunting yard noises calculated from models are drawn with solid lines calculated on the grounds of their models [11].

It follows from Fig. 4 that the percentage of respondents who feel very high annoyance of noise generated by wind turbines is much higher than the fraction of those who sense annoyance caused by transportation and industrial noise. Very high annoyance of wind power plants is sometimes compared to this of a railway shunting yard. Such resemblance is likely to follow from the fact that both noise sources are active in the night when transportation and industrial noise is usually lower. The results indicates the necessity to work out statutory limits for wind turbine noise differentiation between the day and the nighttime.

The attempt to determine exposure-response curves for wind power plant sounds in conditions "outside" and "inside" dwellings has been presented by Janssen [14].

To develop a model for annoyance of noise generated by wind turbines and determined exposure-response curves, 
a large base of data from many counties would be required. To date, comprehensive studies in this direction were carried out mainly in The Netherlands and in Sweden [11]. The result of the comparative study on wind turbine noise outside dwelling house in these countries carried out by means of a survey questionnaires filled in by respondents deriving no economic benefits from these facilities is shown in Fig. 5. The noise was assessed in a 5 -degree scale ( 1 = "do not notice"; 2 = "notice, but not annoyed"; 3 = "slightly annoyed"; 4 = "rather annoyed"; $5=$ "very annoyed") depending on the sound level on the building's facade.

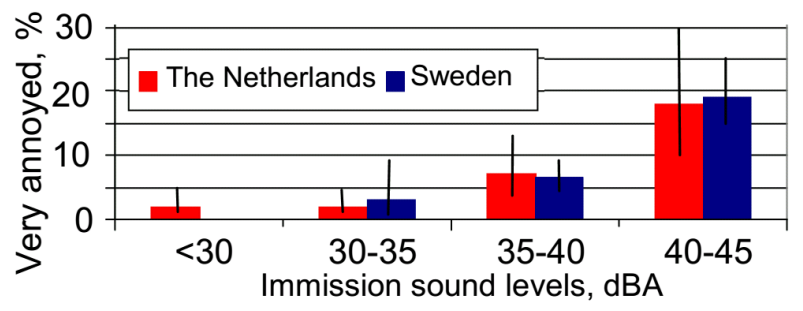

Fig. 5. The percentage of respondents to questionnaire surveys carried out in The Netherlands $(n=586)$ and in Sweden $(n=1095)$ assessing the wind turbine noise as very annoying. The Respondents did not benefit economically from wind power plants. Vertical lines represent $95 \%$ reliability intervals [14].

It follows from Fig. 5 that there is no difference between fractions of respondents assessing the noise as a very annoying in individual sound level ranges. This indicates absence of cultural difference in sound perception or assessment between Sweden and The Netherlands.

If a similar research was carried out also in other countries (including Poland), the set of their results could be used as a base for construction of a exposure-response curve for the noise coming from wind power plants.

Apart from subjective assessments, objective research on the impact of infrasound on humans has been also carried out and revealed some changes in EEG and ECG signal recordings $[15,16]$.

\section{Experimental research}

Experimental research was carried out with a test group of 35 individuals aged from 19 to 23. Details of the experimental procedure are given in [17]. From acoustic signal registered at a distance of 750 meters from a wind turbine, frequencies above 20 were then filtered out. The acoustic signal obtained this way was presented to the test participants for 20 minutes. The level of the applied acoustic stimulus was $\mathrm{SPL}=91.6 \mathrm{~dB}(\mathrm{LIN}) / 39.2 \mathrm{~dB}(\mathrm{~A})$. Figure 6 shows the spectrum of the acoustic signal the subjects were exposed to. Before and after the test, member of the group responded to the Thayer's test measuring the activation level.

The Thayer activation list, known also as the Activation Deactivation Adjective Check List (AD ACL) has been proposed by Robert E. Thayer, professor of psychology at the California State University in Long Beach, USA [18]. Polish adaptation was worked out by Helena

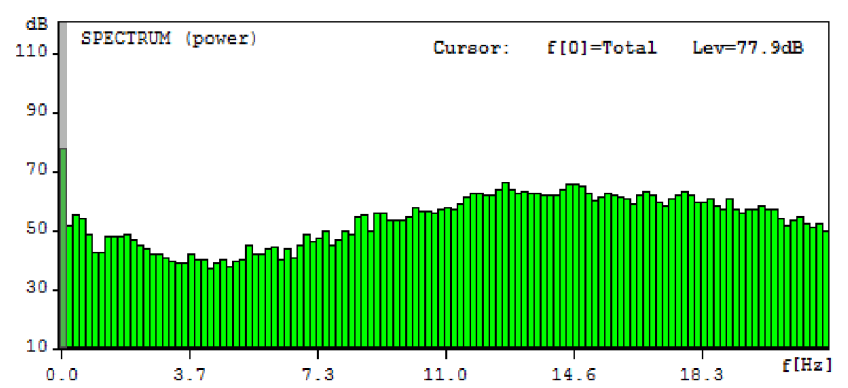

Fig. 6. Acoustic spectrum of the applied infrasound noise.

Grzegołowska-Klarkowska [19]. The scale is commonly considered as a good tool useful in subjective assessment of human mood.

Thayer has proposed to divide the activation scale into four subscales:

- General Activation (GA) - equivalent to Energytype activation in which a person can be described as active, energetic, vigorous, lively, full-of-pep;

- High Activation (HA) - called also the Tensiontype activation - a person is jittery, intense, fearful, clutched-up, tense;

- General Deactivation (GD) - equivalent to Calmness-type activation — a respondent feels placid, calm, at-rest, still, quiet;

- Deactivation-Sleep (DS) - described also as the Tired-type activation - a person feels sleepy, tired, drowsy, wide-awake, wakeful.

The activation level was measured before and after completion of exposure to infrasound. Table I summarizes basic descriptive statistics for 4 activation level subscales, i.e. General Activation (GA), High Activation (HA), General Deactivation (GD), and DeactivationSleep (DS).

TABLE I

Descriptive statistics of the activation level before and after exposure to infrasound noise.

\begin{tabular}{l|c|c|c|c|c|c}
\hline \hline & $\mathrm{N}$ & av. & med. & min. & max. & s.d. \\
\hline GA_before & 35 & 12.97 & 13 & 8 & 19 & 2.717 \\
GA_after & 35 & 12.77 & 12 & 10 & 18 & 2.691 \\
\hline HA_before & 35 & 7.63 & 7 & 5 & 14 & 2.556 \\
HA_after & 35 & 8.37 & 8 & 5 & 15 & 2.556 \\
\hline GD_before & 35 & 15.23 & 15 & 12 & 19 & 2.045 \\
GD_after & 35 & 15.46 & 15 & 9 & 20 & 2.227 \\
\hline DS_before & 35 & 12.17 & 12 & 7 & 17 & 2.651 \\
DS_after & 35 & 11.83 & 12 & 8 & 16 & 2.407
\end{tabular}

Results of the performed analysis concerning the activation level change before and after exposure to infrasound are shown in Table II. 


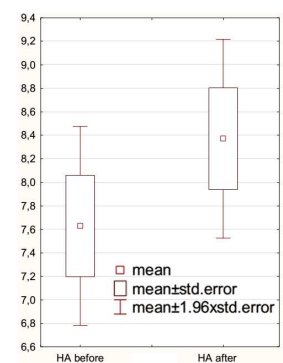

Fig. 7. High Activation level change before and after exposure to infrasound.
A statistically significant decrease of the High Activation after exposure to infrasound has been found, as presented in Fig. 7.

The performed analyses revealed statistically significant effect of a 20-minute exposure to infrasound wave coming from wind turbine in the form of increase of the High Activation level, i.e. the psychophysiological measure that can be defined with such verbal descriptions as jittery, intense, fearful, clutched-up, tense. No statistically significant changes in other activation measures have been found.

$t$-test for dependent samples of activation level before and after the actual test.

TABLE II

\begin{tabular}{|c|c|c|c|c|c|c|c|c|}
\hline & av. & s.d. & $\overline{N N}$ & 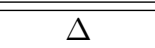 & s.d. $-\Delta$ & $\bar{t}$ & $\overline{\mathrm{d} f}$ & $\overline{p p}$ \\
\hline $\begin{array}{l}\text { GA_before } \\
\text { GA_after }\end{array}$ & $\begin{array}{l}12.97 \\
12.77\end{array}$ & $\begin{array}{l}2.716 \\
2.691\end{array}$ & 35 & 0.20000 & 3.197 & 0.3701 & 34 & 0.713 \\
\hline $\begin{array}{l}\text { HA_before } \\
\text { HA_after }\end{array}$ & $\begin{array}{l}7.62 \\
8.37\end{array}$ & $\begin{array}{l}2.556 \\
2.556\end{array}$ & 35 & -0.74286 & 2.119 & -2.0739 & 34 & $0.045^{*}$ \\
\hline $\begin{array}{l}\text { GD_before } \\
\text { GD_after }\end{array}$ & $\begin{array}{l}15.22 \\
15.45\end{array}$ & $\begin{array}{l}2.044 \\
2.227\end{array}$ & 35 & -0.22857 & 2.365 & -0.5718 & 34 & 0.571 \\
\hline $\begin{array}{l}\text { DS_before } \\
\text { DS_after }\end{array}$ & $\begin{array}{l}12.17 \\
11.82\end{array}$ & $\begin{array}{l}2.651 \\
2.406\end{array}$ & 35 & 0.34286 & 2.775 & 0.7309 & 34 & 0.469 \\
\hline
\end{tabular}

*Statistically significant results $p<0.05$

\section{Conclusions}

The wind power industry grows dynamically all over the world and Poland is no exception in this respect. However, vibroacoustic issues assessed by means of objective and subjective methods and reported in available literature of the subject remain still insufficiently recognized and examined in Poland. One can speculate that the scale of problems related to sound and vibration emissions generated by wind turbines will increase in this country. However, in view of cultural differences it is rather difficult to predict whether Poles will assess annoyance subjectively in the same way as the Swedes or the Dutch. Therefore, there is an urgent need to undertake in-depth research on vibroacoustic phenomena relating to wind farms oriented at both scientific and utilitarian (regulatory) aspects of the problem.

Experimental tests of the impact of a 20-minute exposure to infrasound signal with spectrum characteristic for wind turbines demonstrated statistically significant effect in the form of an increase of tension-type activation.

\section{Acknowledgement}

This study is a part of the N N501 247740 research project supported by the National Science Centre.

\section{References}

[1] http://www.elektrownie-wiatrowe.org.pl.

[2] G.P. van den Berg, J. Sound Vibr. 277, 955 (2004).

[3] M. Wolsink, M. Sprengers, Proc. of 6th International Congress on the Biological Effects of Noise, ICBEN, Nice 1993, p. 235.

[4] M. Wolsink, M. Sprengers, M. Keuper, T.H. Pedersen, C.A. Westra, Proc. of the European Community Wind Energy Conference, Lubeck, Travemünde 1993, p. 273.
[5] M.V. Lowson, Proc. of Internoise 96, 479 (1996).

[6] K. Persson, E. Öhrström, J. Sound Vibr. 250, 65 (2002).

[7] E. Pedersen, K. Persson, J. Acoust. Soc. Am. 116 , 3460 (2004).

[8] E. Pedersen, Human response to wind turbine noise - perception, annoyance and moderating factors, The Sahlgrenska Academy, Göteborg 2007.

[9] E. Schreurs, J. Jabben, E. Verhejien, Proc. Euronoise 2009, 3975 (2009).

[10] G.P. van den Berg, Proc. Euronoise 2009, 3965 (2009).

[11] E. Pedersen, G.P. van den Berg, R. Bakker, J. Bouma, J. Acoust. Soc. Am. 126, 634 (2009).

[12] H.M.E. Miedema, H. Vos, R. de Jong, J. Acoust. Soc. Am. 107, 3245 (2000).

[13] M. Golec, Z. Golec, C. Cempel, First Int. Meeting on Wind Turbine Noise: Perspectives for Control, Berlin 2005.

[14] S.A. Janssen, A.R. Eisses, E. Pedersen, Euronoise 2009, 1472 (2009).

[15] C. Kasprzak, Acta Phys. Pol. A, 118, 87 (2010).

[16] C. Kasprzak, Acta Phys. Pol. A 121, 61 (2012).

[17] C. Kasprzak, Acta Phys. Pol. A 123, 980 (2013).

[18] R.E. Thayer, Psychophysiology 7, 86 (1970).

[19] H. Grzegołowska-Klarkowska, in: Regulatory functions of temperament, Ed. J. Strelau, Wydawnictwo PAN, Warszawa 1982, p. 93. 